\title{
A CONTINUIDADE DE UMA GRANDEZA E O CONTACTO ENTRE PONTOS GEOMÉTRICOS NO TRATADO “ACERCA DO CONTÍNUO" DE TOMÁS BRADWARDINE
}

\author{
Lídia Queiroz \\ Gabinete de Filosofia Medieval \\ do Instituto de Filosofia da Universidade do Porto
}

O Tractatus de continuo de Tomás Bradwardine foi redigido no contexto da controvérsia originada pela emergência da defesa de um atomismo matemático na Universidade de Oxford, durante a primeira metade do século XIV. Retratando a questão de compositione continui, sob diversos ângulos, Bradwardine denuncia os absurdos que a defesa da compositio continui ex indivisibilibus engendra. Este tratado assume uma particularidade notável uma vez que foi escrito seguindo o arquétipo de ciência sistemática e precisa que constitui os Elementos ${ }^{1}$ de Euclides, ou seja, as 151 "Conclusões"2 que constam do mesmo são derivadas a partir de um conjunto de princípios primeiros que designou por "definições" e "suposições". Ao longo dessas "Conclusões" ou "Proposições" o filósofo procura refutar as diferentes hipóteses atomísticas, colocando em evidência a impossibilidade destas serem verdadeiras pois colidem com princípios básicos de todos os domínios do conhecimento, nomeadamente, e em especial, com os da geometria euclídea. Esta é, então, uma obra de carácter matemático, tanto pela forma axiomática como o autor expõe as suas ideias, bem como pelos conteúdos expressos. Com efeito, o tratado representa "o apogeu da ratio mathematica contra o atomismo do século XIV"3, apresentando-se

${ }_{1}^{1}$ Para uma introdução geral aos Elementos de Euclides, por meio de uma abordagem de tópicos muito diversificados, vide, v. g.: Elementos. Introducción de L. Vega, Traducción y Notas de M. L. P. Castaños, Vol. 1 (2000), pp. 7-48 e 123-151.

$2 \mathrm{O}$ manuscrito de Erfurt acrescenta mais duas conclusões a este número: as conclusões 107A e 121A, da edição crítica de John Murdoch.

3 J. Murdoch, "Naissance et développement de l'atomisme au Bas Moyen Âge Latin" (1974), p. 24.

Philosophica, 34, Lisboa, 2009, pp. 245-258 
como "a obra mais impressionante acerca do problema escrita durante a Idade Média"4.

Na Idade Média, isto é, a partir da tradução da Física, a questão do continuum era analisada à luz da filosofia de Aristóteles. Duas obras deste filósofo são incontornáveis para a compreensão do problema da continuidade, a saber: as Categorias e a Física. Lê-se nas Categorias: "Das quantidades, umas são discretas e outras contínuas (...). São quantidades discretas, por exemplo, o número (...); são quantidades contínuas a linha, a superfície, o corpo e, além destas, o tempo e o lugar."5 Para o Filósofo, o contínuo é, antes de mais, uma quantidade. E, por definição, uma quantidade una, embora composta de partes sem fim: trata-se de uma quantidade cujas partes "unem-se num limite comum", sendo estas divisíveis em partes infinitamente divisíveis?.

Relativamente a esta característica definitória do contínuo, o de ser uno, refira-se ainda que um contínuo é composto de partes cujos limites são partilhados (daí que não haja fronteiras) mas que, não obstante, podem ser destacadas do todo em causa ${ }^{8}$. Embora um contínuo seja um todo unificado, isso não obsta a que falemos também acerca das "partes" das coisas contínuas e ainda de posições ou "pontos" dentro desse contínuo; aliás, assume-se como tarefa a sua determinação na unidade. Trata-se do "problema da fixação de partes e posições dentro da unidade essencial do contínuo". ${ }^{9}$ Para além disso, há que conseguir perceber e explicar como é que uma determinada posição ou parte específica está relacionada com as outras. Agora, a grande questão que se pode colocar (e que está afinal na base da redacção do Tractatus de continuo) é a seguinte: "é claro que ambos as partes e os pontos estão contidos no contínuo ${ }^{10}$. Mas não é claro

4 J. Murdoch e E. Synan, "Two Questions on the Continuum: Walter Chatton (?), O.F.M. and Adam Wodeham, O.F.M.” (1966), p. 221.

5 Aristóteles, Categorias, 6, 4b20-25.

6 Vide Aristóteles, Categorias, 6, 5a1-15.

7 Aristóteles, Física, VI, 1: “....nós vimos que nada contínuo era divisível em partes sem partes" (231b11); "todo o contínuo é divisível em divisíveis ad infinitum" (231b15).

8 Note-se todavia que, para Aristóteles, as partes desse todo (e os limites comuns que partilham) não têm uma existência actual até que uma divisão seja realizada, pois antes dessa operação as partes de um contínuo encontravam-se nele apenas potencialmente (em acto, não existiam as chamadas "fronteiras comuns" das partes - estas só se desvelam se a análise do pensamento as fizer sair da sua potencialidade). Cfr. Aristóteles, Física, VIII, 8, 262a21-22. Tais partes existiam nos contínuos, in potentia, não são "construídas" pelo sujeito cognoscente. Vide J. Murdoch, "William of Ockham and the Logic of Infinity and Continuity" (1982), p. 202.

9 J. Murdoch, Geometry and the Continuum in the Fourteenth Century: a Philosophical Analysis of Thomas Bradwardine's Tractatus de Continuo (1957), p. 5.

10 Veja-se as razões dessa evidência in J. Murdoch, Geometry and the Continuum in 
que ambos possam compor o contínuo"11. Às partes, sendo elas mesmas contínuas, bem se lhes pode atribuir o papel de conferir continuidade a uma grandeza, mas e os pontos? A ser possível que o ponto fosse um componente dos contínuos ter-se-ia de explicar "como é que a extensão, isto é, um contínuo, pode ser produzida a partir de partes inextensas" 12 . No fundo, este é o desafio teórico a que os filósofos atomistas do século XIV não puderam escapar, ao defenderem que um contínuo compõe-se de indivisíveis. Se fosse por meio do contacto entre os pontos, indivisíveis inextensos, que se formaria um contínuo, então haveria que esclarecer quais são as condições em que tal contacto pode dar-se.

Aristóteles entabulara aquela discussão na Física, apresentando o espectro das possibilidades do contacto e concluindo que este, entre os indivisíveis pretensamente constituintes de um qualquer contínuo, é impossíve $1^{13}$. E inicia a fundamentação desta conclusão do seguinte modo: "se os pontos fizessem um contínuo, eles teriam de ser ou contínuos ou contíguos"14. Mas contínuos não são porque nem sequer têm extremidades ${ }^{15}$; nem entre eles existe contiguidade, porque para tal eles deveriam tocar-se, estar juntos. Mas o contacto só poderia dar-se entre: (1) o todo (de um ponto) com o todo (do outro), ou (2) a parte (de um) com a parte (do outro), ou (3) a parte (de um) com o todo (do outro). Constata-se que (2) e (3) são impossíveis porque os pontos não têm partes ${ }^{16}$, e que (1) também o é, pois se o todo toca o todo os pontos não serão contínuos já que a continuidade requer que haja partes separadas no espaço (e se os indivisíveis estivessem em contacto o todo com o todo, as partes do con-

the Fourteenth Century: a Philosophical Analysis of Thomas Bradwardine's Tractatus de Continuo (1957), pp. 6-7.

11 J. Murdoch, Geometry and the Continuum in the Fourteenth Century: a Philosophical Analysis of Thomas Bradwardine's Tractatus de Continuo (1957), p. 6. Relativamente à distinção entre "estar contido em" e "compor" vide, v. g., Tomás Bradwardine, De continuo, Conclusio 55 (“...et continetur et componitur...”).

12 Aristóteles, Metafísica, XII, 10, $1075 \mathrm{~b} 29$.

13 Um argumento mais de carácter "intuitivo" do que "matemático". In J. North, "Astronomy and Mathematics" (1992), p. 149.

14 Aristóteles, Física, VI, 1, 231 a29.

15 Vide Aristóteles, Física, VI, 1, 231a21-22 e 231a26-29. Só pode ter extremidades o que possui partes e um ponto geométrico não as possui. Portanto, os indivisíveis não podem ser contínuos pois nem sequer têm limites que possam ser partilhados com os outros indivisíveis, tornando-se limites comuns. A tese da compositio ex indivisibilibus implicaria uma contradição formal entre termos (contradictio in terminis), pois o "indivisível" é o que não pode ser dividido por não possuir outra parte que não seja já a última (a única) e o "contínuo" é aquilo cujas partes extremas são um só.

16 Note-se que o sucesso deste argumento circunscreve-se ao domínio dos indivisíveis inextensos. 
tínuo seriam indistinguíveis). Logo, os contínuos não podem ser compostos de indivisíveis ${ }^{17}$. Em suma: os indivisíveis não podem estabelecer um contacto como as partes de um contínuo o fazem, pois não apresentam os requisitos necessários, na perspectiva aristotélica, para que tal contacto pudesse realizar-se. Por conseguinte, não se pode sustentar que os indivisíveis possam constituir um contínuo pelo alegado contacto entre si. Se se conseguisse demonstrar que os pontos também se encontram ligados entre si, que existe um meio qualquer de contacto, poder-se-ia inclú́-los no conjunto dos componentes do contínuo, mas como não se vislumbra como possível essa conexão, aqueles ficam arredados da composição dos contínuos. Em suma: chega-se à conclusão da infinita divisibilidade das grandezas por reductio ad absurdum, "porque se ele [o contínuo] fosse divisível em indivisíveis, um indivisível estaria em contacto com outro, uma vez que as extremidades das coisas contínuas umas com as outras são uma e em contacto"18. E elucidou-se que os indivisíveis não podem estar em contacto, logo, eles não são elementos constituintes de um contínuo.

A tese aristotélica da impossibilidade da composição dos contínuos por pontos ou indivisíveis manteve-se praticamente imperturbada durante a Idade Média, contando ademais com uma atenção significativa por parte dos autores da escolástica que, seguindo na mesma linha de pensamento, avançaram na análise da questão ${ }^{19}$. Somente no período tardo-medieval, alguns autores latinos assumiram posições discordantes da concepção clássica vigente anti-indivisibilista ${ }^{20}$, ressurgindo então uma teoria que tinha sido defendida (e discutida) na Antiguidade: o atomismo. E o atomismo medieval é de carácter matemático: os indivisibilia são encarados como pontos geométricos, isto é, absolutamente inextensos ${ }^{21}$.

17 Cfr. Aristóteles, Física, VI, 1, 231a21-231b6.

18 Aristóteles, Física, VI, 1, 231b16-18.

19 Vide J. Murdoch, Geometry and the Continuum in the Fourteenth Century: a Philosophical Analysis of Thomas Bradwardine's Tractatus de Continuo (1957), p. 15.

20 Mencione-se, no entanto, que a primeira forma de atomismo medieval foi elaborada pelos teólogos mutazilitas do século IX, que defenderam a ideia de que toda a grandeza é composta por pontos-átomos sem extensão, criticando a posição aristotélica. Porém, não temos qualquer indicação de que os atomistas cristãos medievais ou os seus opositores se tivessem inspirado nas doutrinas daquele movimento islâmico para as suas próprias concepções, embora discutam também um atomismo matemático. Murdoch sustenta que o atomismo medieval do dealbar do século XIV constitui "uma criação independente". Para uma exposição mais pormenorizada acerca da ponte(?) que se estabelece entre o atomismo islâmico medieval e o atomismo cristão latino, vide J. Murdoch, "Naissance et développement de l'atomisme au Bas Moyen Âge Latin" (1974), p. 13.

21 Uma outra ressalva urge ser feita. Qualifica-se o atomismo medieval como um atomismo matemático. As posições de Harclay e de Chatton são interpretadas por 
Quem tentasse estabelecer no panorama universitário o atomismo, teria de ser capaz não só de derrubar o sistema argumentativo aristotélico contra a composição indivisibilista dos contínuos mas também os novos argumentos de carácter matemático que, principalmente a partir do final do século XIII, se acrescentaram àqueles da doutrina aristotélica ${ }^{22}$. Se os autores se serviam de uma imagem dos indivisíveis como pontos matemáticos, teriam então depois que se debaterem com o problema de explicar como é que por meio destes se forma uma grandeza (ou, por outras palavras, encontrar uma saída para a ideia expressa pela seguinte expressão medieval: unum indivisibile additum alteri non facit maius ${ }^{23}$. E isto porque uma grandeza é uma quantidade contínua e mensurável ${ }^{24}$ e um indivisível, se é como um ponto matemático, corresponde a uma grandeza zero: designando o término de uma dada quantidade, já nem se trata de uma quantidade. Uma grandeza é uma entidade susceptível de medida e os pontos matemáticos não têm dimensões.

Respondendo então a esta exigência de refutação do argumento aristotélico, os defensores do atomismo no final da Idade Média teriam de explicar que tipo de ligação se estabelece entre os indivisíveis para que se perceba como é que um corpo, por exemplo, poderia ser formado a partir de entidades inextensas. Os filósofos atomistas medievais explicam que é possível um "contacto" entre os indivisíveis, que formariam as grandezas, com base numa fonte de inspiração peculiar, a saber: o axioma da congruência de Euclides. Este axioma foi aplicado nas provas dos teoremas que constituem as Proposições 4 e 8 do Livro I dos Elementos, e ainda na Proposição 24 do Livro III (os chamados "teoremas da congruência" em Euclides). A demonstração realiza-se pela manipulação dos objectos geométricos praticando a sua sobreposição (ex superpositione), sendo recorrente o uso da terminologia "aplicar o... a" ou "colocar sobre" (sobrepõem-se linhas, pontos e ângulos) e a constatação do resultado expresso pelo verbo "coincidirá". As figuras coincidem, são iguais entre si (cfr.

Bradwardine como sendo ambas construídas sobre a noção de indivisível como um ponto matemático. O mesmo considera Wodeham. No entanto, refira-se, os indivisíveis de Chatton não são representáveis por pontos uma vez que são como entidades físicas. Vide J. Biard e J. Celeyrette (eds.), De la théologie aux mathématiques. L'infini au XIV siècle (2005), p. 31.

22 Os contributos de, por exemplo, João Duns Escoto (Opus oxoniense) e Roger Bacon (Opus maius).

${ }^{23}$ In, v. g., Henrique de Harclay: Ordinary Questions (ed. by Mark G. Henninger/transl. by Raymond Edwards e M. Henninger), 2008, vol. II, p. 1056.

24 É uma redundância afirmar, como se lê tantas vezes em alguma literatura, "grandeza contínua", uma vez que "toda a grandeza é contínua" (cfr. Aristóteles, Física, IV, 11, 219a11). 
Livro I, Noção Comum 7) ${ }^{25}$. Aquilo que os atomistas medievais fazem é apoderarem-se deste axioma convertendo-o na solução que as concepções filosóficas indivisibilistas necessitavam para que não fossem acusadas de inconsistência: estes autores descobrem no contacto matemático que se observa nas figuras geométricas colocadas umas sobre as outras (a superpositio) o contacto das linhas e dos pontos que nelas existem. No fundo, a crença dos partidários de teses atomísticas é que os átomos assim sobrepostos estão em contacto e permanecem distintos. Bradwardine assentirá em que a sobreposição se assuma como o meio de contacto entre os indivisíveis, mas colocará em causa que por meio dela se forme um contínuo, isto é, pela existência de indivisíveis imediatos.

Bradwardine apresenta como a definição inaugural do tratado "Um contínuo é uma quantidade cujas partes estão mutuamente unidas" "26, parecendo clara a sua proximidade com a tese aristotélica de que "duas coisas são contínuas quando os limites de cada uma tornam-se idênticos e são mantidos juntos"27. Não obstante, a definição de contínuo proposta por Bradwardine apresenta uma diferença significativa relativamente à de Aristóteles, pois embora também insista na ideia da união das partes numa só entidade (copulatio), não faz qualquer referência à fundamental noção aristotélica de "extremidades" (termini). Assim, as partes de uma grandeza poderiam constituir essa unidade mas por meio da sobreposição (superpositio), por exemplo. Pelo menos, pela definição dada, tal possibilidade de modo de união das ditas partes não fica arredada. O mesmo já não pode ser defendido no contexto da definição aristotélica pois, para

25 Dada a atribulada história das versões, edições e comentários a que os Elementos de Euclides se sujeitaram (cfr. J. Murdoch, "Euclid: Transmission of the Elements" (1971), p. 437), este axioma encontra-se numerado diferentemente. Na edição crítica de Heiberg, ele corresponde ao axioma 7 que, simplificando, constitui o quarto axioma de Euclides porque outros foram suprimidos. Na versão de Campano corresponde ao axioma 8 e na Geometria speculativa de Bradwardine, por exemplo, ele é apresentado em nono lugar (cfr. p. 24, ed. de G. Molland, 1989). Este é o axioma da congruência de Euclides, na versão de Adelardo de Bath Campano de Novara: "Si aliqua res superponatur alteri appliceturque ei nec excedat altera alteram, ille sibi invicem equales erunt".

26 Tomás Bradwardine, De continuo, Definitio 1: "Continuum est quantum cuius partes ad invicem copulantur". "However, we should note that Bradwardine does not (...) postulate the existence of the proper subject-genus of his investigation, viz., continuous quantity", J. Murdoch, Geometry and the Continuum in the Fourteenth Century: a Philosophical Analysis of Thomas Bradwardine's Tractatus de Continuo (1957), p. 97.

27 Aristóteles, Física, V, 3, 227a11-12. 
Aristóteles, as partes de um contínuo constituem uma única quantidade pelo facto dos extremos de cada uma serem um só em acto. Por outras palavras, cada parte só é "parte" em potência, pois em acto temos antes um todo. À luz da definição do Estagirita, a sobreposição de duas partes não permite o mesmo resultado (isto é, uma grandeza) pois as partes mantêm-se distintas uma da outra, em acto, figurando como duas quantidades juntas ou contíguas (e não uma só quantidade). Segundo distinções expressas na Física, é contíguo aquilo que, estando em sucessão, está também em contacto ${ }^{28}$. O contínuo é, então, uma espécie do género contí$g u o^{29}$, porque nem tudo o que é contíguo é contínuo ${ }^{30}$. Os contínuos são quantidades nas quais os limites das partes não só se tocam como se tornam um e o mesmo, dando-se num mesmo lugar esse contacto entre os limites juntos ${ }^{31}$.

Ora, sendo Bradwardine um simpatizante da filosofia de Aristóteles, parece estranho que tenha apresentado uma definição de contínuo que dá azo a esta maior amplitude de modos de união das partes, abrindo, assim, o lugar à intromissão de elementos alheios e até contrários à física aristotélica. Com efeito, não se exigindo a união das partes numa só quantidade pelos seus extremos, os defensores do indivisibilismo podem encontrar nessa definição um terreno mais fácil para avançarem com as suas concepções, declarando então que a união das partes de uma grandeza dá-se pela sobreposição. E assim ofereceriam uma resposta à exigência de um meio de contacto entre as partes (indivisíveis). Porém, as tentativas teóricas de carácter indivisibilista foram seriamente atacadas por Bradwardine e desmontadas nos seus inúmeros erros, embora no início do tratado o autor esteja realmente a presentear o adversário com uma definição de contínuo que proporciona uma maior abertura. Com o desenrolar da argumentação no tratado, constatámos que tal espírito de abertura não resulta em mais do que lhes conceder, inicialmente apenas, o "benefício da dúvida" 32 . Sendo o objectivo de Bradwardine o de erigir uma refutação

28 In Aristóteles, Física, V, 3, 227a6-7.

29 In Aristóteles, Metafísica, XI, 12, 1069a5.

30 Aristóteles, Metafísica, XI, 12, 1069a1-11: “Aquilo que, sendo sucessivo, toca, é contíguo. (...) o sucessivo não toca necessariamente, mas aquilo que toca é sucessivo. E se uma coisa é contínua, ela toca, mas se ela toca, ela não é necessariamente contínua".

31 Acerca da "singularidade do lugar das extremidades em contacto", Murdoch menciona uma fragilidade do pensamento de Aristóteles que Bradwardine, por ter seguido uma outra via, conseguiu evitar. Vide J. Murdoch, Geometry and the Continuum in the Fourteenth Century: a Philosophical Analysis of Thomas Bradwardine's Tractatus de Continuo (1957), pp. 80-81.

32 "Bradwardine has not only refrained from giving the 'alternative' definition of a continuum as that divisible into infinitely divisible parts, but has also refrained 
sistemática e definitiva do atomismo em todas as suas formas doutrinais (falsas), o autor apresentou uma definição de contínuo que não tinha por que suscitar qualquer reparo ou voz discordante, por parte de um defensor do indivisibilismo. Sendo pois pacífica, seria um bom ponto de partida para o seu sistema, dado o universal assentimento que poderia reunir por parte de todos.

Bradwardine define o "indivisível" como "o que nunca pode ser dividido" 33 e atribui ao ponto, o indivisível espacial, a característica de ser o "indivisível posicionado"34. A definição de indivisível apresentada por Bradwardine, à partida, também parece adequar-se à ideia de que um indivisível é o que não tem partes. A inexistência de "partes" é exactamente a ideia-chave na definição dada por Euclides para o ponto bem como na discussão aristotélica em torno do contínuo, na crítica que desenvolve contra o atomismo ${ }^{35}$. Ainda assim, como constatámos, Bradwardine não reutiliza aquela ideia na sua definição, apresentando antes uma nova proposta, fazendo recair a atenção na impossibilidade de divisão. Esta mudança operada na concepção de ponto parece servir o seguinte propósito: definindo o indivisível como aquilo que não pode ser dividido, o autor cria uma definição capaz de abarcar um espectro mais amplo de indivisíveis. Referimo-nos à inclusão dos átomos democritianos.

Com efeito, a história da filosofia natural que o autor oxoniense herda retratara já dois tipos de indivisíveis: os extensos (corpóreos) e os inextensos (considerados como pontos geométricos) ${ }^{36}$. Assim, quando o autor avançar na sua crítica ao indivisibilismo, estará a abarcar todo o leque de indivisíveis ideados até então, pois todos têm em comum o facto de, tendo ou não partes, serem indivisíveis. Por conseguinte, não é de estranhar que o famoso argumento de Aristóteles da impossibilidade de um meio de contacto entre os indivisíveis, por carecerem de partes, não seja mencionado e trabalhado no tratado. Não tendo Bradwardine valorizado esse aspecto da natureza dos indivisíveis, isto é, o da carência de partes (deixando em aberto a possibilidade de as terem), o seu sistema

from mentioning 'boundaries' in his assertion of the connection of the parts of the continuum. He gives, as it were, the benefit of the doubt to his opponents before proceeding to his refutation of them", J. Murdoch, Geometry and the Continuum in the Fourteenth Century: a Philosophical Analysis of Thomas Bradwardine's Tractatus de Continuo (1957), p. 90.

33 Cfr. Tomás Bradwardine, De continuo, Definitio 7.

34 Cfr. Tomás Bradwardine, De continuo, Definitio 8.

35 Cfr. Euclides, Elementos, I, Definição 1; Aristóteles, Física, VI, 1, 231a26-28.

36 Estas duas grandes linhas de concepção dos átomos expressas in Tomás Bradwardine, De continuo, Conclusio 31. 
demonstrativo acabará por se desenvolver mantendo afastado esse argumento.

Ao longo do desenvolvimento das primeiras "Proposições" do tratado, Bradwardine revela uma boa parte da originalidade do seu pensamento. Nessas conclusões, ele apresenta algumas propriedades e relações particulares que os indivisíveis podem estabelecer entre si nas grandezas, realizando esta tarefa num contexto independente ainda do debate em torno da questão da composição indivisibilista dos contínuos e tendo como pano de fundo o universo da geometria. As possíveis relações entre os indivisíveis designadas pelas expressões "estar no mesmo lugar indivisível", "ser imediato a" e "estar à mesma distância de" correspondem, respectivamente, à descrição de três termos técnicos no interior deste tratado: a "imposição", a "sobreposição" e a "separação". No contexto de descrição das relações que entidades geométricas podem estabelecer entre si e do desenvolvimento do seu sistema, o distare ad latus, que designa a separação, acaba por ser uma ideia secundária (daí que nem sequer tenha sido apresentada a sua definição). São então as noções de impositio e superpositio que estão no centro das atenções da análise ao contínuo.

Encontramos o significado dos termos "sobreposição" e "imposição" logo no início do tratado. Debrucemo-nos, primeiramente, sobre a ideia de sobreposição, atentando na Definição 15: "Ser sobreposta uma linha a outra linha, parcial ou totalmente, é a própria linha a aderir à outra em absoluto, sem um meio (entre esta e a outra linha), segundo o comprimento do todo ou da parte" 37 . A noção de sobreposição era por demais conhecida pelos intelectuais da Idade Média que encontram na geometria de Euclides, no chamado "axioma da congruência", uma enunciação daquela ideia. Esse princípio consiste na afirmação de que "as coisas que coincidem entre si são iguais entre si" 38 . Nos Elementos procede-se à sobreposição de figuras geométricas distintas pela deslocação de uma (assumindo-se que o movimento não a deforma) e a sua colocação sobre a outra. Assim, figuras geométricas iguais são aquelas em que, aplicadas uma à outra por meio da sobreposição, se verifica imediatamente a evidência da sua igualdade, pois nenhuma excede a outra, revelando antes uma perfeita coincidência de medidas, coincidindo nos seus limites. E a sobreposição de duas coisas ocorre sempre que uma se coloca em cima da outra, ou debaixo ou imediatamente junta lado a lado (três possibilida-

37 "Lineam linee superponi partialiter vel totaliter est ipsam secundum longitudinem totius vel partis simpliciter sine media adherere alteri".

38 Vide supra n. 25. 
des), sem que haja entidade alguma ${ }^{39}$ ou qualquer espaço entre elas que as separe. Sempre que duas grandezas estivessem sobrepostas, os seus componentes estabeleceriam relações entre si.

Reconhece-se que o primeiro texto em que se aborda a questão do contínuo à luz da noção de sobreposição é o De lineis insecabilibus, atribuído a Aristóteles ${ }^{40}$, e muitos foram os autores que durante a Idade Média utilizaram esta noção para debater aquela questão. Para além de Bradwardine, filósofos como Gerardo de Odon, Gregório de Rimini e Marco Trivisano também o fizeram e até, curiosamente, Gerardo de Odon criou uma terminologia em torno daquela questão muito próxima da de Bradwardine, comparando a superpositio, a juxtapositio (o correspondente à noção bradwardiana de impositio) e a distanterpositio ${ }^{41}$. Mas a apropriação da ideia de "sobreposição" por parte de Bradwardine e o seu emprego no estudo das quantidades contínuas corresponde a um projecto mais audaz pelo papel determinante conferido pelo filósofo àquela noção no seu plano de refutação do atomismo. Com efeito, este conceito não só serve de terminologia para apreciação descritiva de objectos geométricos como sendo o termo que expressa a relação de proximidade imediata entre entidades, bem como é ainda eleito como a noção explicativa do desmoronamento do edifício do indivisibilismo.

A maior façanha argumentativa, construída por Bradwardine, apoia-se então na ideia de superpositio. Ele começa por considerar aquilo que os filósofos atomistas tinham sustentado: que o que estrutura a continuidade de grandezas é a sobreposição de indivisíveis. Começando por consentir na ideia de que a sobreposição possa explicar o meio de contacto entre os indivisíveis, ele avança depois para a demonstração de que nenhuma forma de sobreposição possível para entidades geométricas origina continuidade. A posição aristotélica acerca de uma possível composição indivisibilista das grandezas era muita clara: tal não é aceitável dado que os indivisíveis ou pontos não podem estabelecer um contacto entre si. No entanto, vários foram os autores que intentaram imaginar outras possibilidades que pudessem dar conta do contacto entre estas entidades indivisíveis e inextensas. Podemos, a título ilustrativo, imaginar a seguinte acção com dois sólidos geométricos: sobre um cubo seja colocado um outro cubo de dimensões iguais, de maneira a que as suas arestas coincidam na perfeição. Verifica-se então que uma das superfícies do cubo fica em contacto total com uma das superfícies do outro cubo. Ora, se se dá essa coincidência total das superfícies, o mesmo se diz acerca das linhas

\footnotetext{
39 Nem sequer pontos. Vide Tomás Bradwardine, De continuo, Conclusio 8.

40 Cfr. Aristóteles (?), Acerca das Linhas Indivisíveis, 971a22-26.

41 In V. Zoubov, "Walter Catton, Gerard d'Odon et Nicolas Bonet" (1959), p. 270.
} 
e, por consequência, dos pontos que elas contêm. Agora, se em circunstâncias como esta admite-se que os pontos contidos nas linhas da superfície de um sólido estão em contacto com os pontos da outra superfície, existirá verdadeiramente uma razão que impeça que se defenda que os pontos contidos numa só grandeza, ou os indivisíveis, possam manter um contacto entre si?

Bradwardine debruçou-se sobre esta questão a partir das noções de sobreposição e imposição. Ele mostra que os indivisíveis podem estabelecer uma relação de proximidade imediata entre si mas a sobreposição exprime apenas o mero contacto entre aqueles. Esgotando todas as formas de sobreposição possíveis para os indivisíveis, constata-se que não se verifica a constituição de um todo unificado. Em nenhum caso a sobreposição origina continuidade pois não "se converte" em imposição. Ora, sendo assim, a hipótese da continuidade derivada da existência de indivisíveis imediatos (ex indivisibilibus immediatis) que se advogava tem de ser rejeitada. Indivisíveis imediatos ou sobrepostos não expressam continuidade, embora estejam em contacto uns com os outros, sem intermediários. Relembremos que a continuidade distingue-se da contiguidade ${ }^{42}$ : dizemos que duas coisas são contíguas quando o término de uma toca a extremidade da outra, ao passo que duas coisas são contínuas quando os seus limites (meramente existentes em potência) são um só, unificados num todo (isto é, coincidem, não se trata pois de limites que se tocam meramente, como acontece no caso da contiguidade).

A Definição 16 apresenta o significado da ideia de imposição, assim: "Ser imposta uma linha a outra linha, segundo a parte ou segundo o todo, é continuar a própria linha na outra segundo o comprimento do próprio todo ou da parte"43. O termo impositio é fundamental para a compreensão da interpretação geométrica que Bradwardine oferece da conexão das partes das coisas contínuas. A verdade é que numa linha contínua podemos sempre observar várias linhas contínuas que, encontrando-se impostas, formam uma e a mesma linha contínua de um determinado comprimento. A imposição acontece quando entidades encaixam-se de maneira a formarem uma só coisa. Todas as partes de um contínuo estão assim unidas mutuamente, ou "impostas", e as fronteiras de cada parte dissolvem-se completamente no todo a que pertencem (note-se o quanto a noção de imposição de Bradwardine nos aproxima da concepção de continuidade em Aristóteles). Apenas a imposição expressa aquilo que é significado pelo verbo copulare.

Da Proposição 9 à Proposição 13 inclusive, Bradwardine realiza um

42 Vide supra notas 28-31.

43 "Lineam linee secundum partem vel secundum totum imponi est ipsam secundum longitudinem ipsius totius vel partis in aliam continuari”. 
estudo das (im)possibilidades de conjugação das três relações geométricas expostas, avaliando criteriosamente as relações de sobreposição e de imposição entre entidades segundo um ponto, dois, uma "parte grande" 44 ou segundo os seus todos. O que de mais importante importa reter como resultado daquelas conclusões é que só a imposição de partes confere a continuidade a uma grandeza (e não a sobreposição). Aliás, de nenhum modo Bradwardine reconhece ser possível a tese da possibilidade da sobreposição estar na origem da continuidade, nem mesmo alegando-se a conjugação daquela relação entre as partes e a imposição, pois a verdade é que as partes não poderão estabelecer entre si ambas as relações. A sobreposição corresponde ao contacto entre as partes ou contiguidade e a imposição à existência de fronteiras comuns ou continuidade. Para Bradwardine, a continuidade não é uma espécie do género contiguidade (como é em Aristóteles) mas são antes duas noções que comportam relações completamente distintas. Por conseguinte, para Bradwardine, se se afirma que duas entidades estão em contacto isso significa desde logo que, então, elas não constituem um contínuo pois estão apenas sobrepostas. Tratando a questão da continuidade em termos geométricos e jogando fundamentalmente com as noções de "sobreposição" e "imposição" ilustradas por meio de relações entre linhas ${ }^{45}$, Bradwardine prova que a "continuidade" só tem correspondência com um daqueles termos.

44 Veja-se o sentido desta expressão in Tomás Bradwardine, De continuo, Conclusio 9.

45 O significado das noções de "sobreposição" e "imposição" é esclarecido em definições ilustradas pelo recurso a linhas geométricas, o que não impede que tais noções sejam também aplicáveis aos restantes objectos da geometria. Ao longo da discussão em torno do contínuo e na maioria das vezes, deve entender-se por "indivisíveis" os pontos matemáticos, mas sem esquecer porém que também as linhas e as superfícies podem ser encaradas como tal e isto porque o ponto é indivisível nas três dimensões, a linha em duas e a superfície em uma. Com efeito, o que distingue os contínuos permanentes (linhas, superfícies e corpos) uns dos outros é o número das suas dimensões, pois "o que é contínuo numa dimensão é comprimento; em duas, largura; em três, profundidade" (Aristóteles, Metafisica, V, 13, 1020a11-12). Assim, "corpo" é aplicável a todas as quantidades contínuas constituídas pelas três dimensões, a "superfície" por duas e a "linha" por uma. As três dimensões são fundamentais para se perceber como é que é possível que, para além dos pontos, as linhas e as superfícies possam ser também encaradas, assumindo-se uma perspectiva diferente, como indivisíveis. Atente-se numa afirmação de Aristóteles, presente na Metafisica, na qual se lê que uma linha é divisível numa dimensão, a superfície em duas, e um corpo é-o em todas, isto é, das três maneiras $(\mathrm{V}, 6,1016 \mathrm{~b} 26-28)$. Por conseguinte, o ponto é o absolutamente indivisível (pois não possui qualquer dimensão) e as linhas e as superfícies serão também indivisíveis: uma linha, indivisível nas duas dimensões que não possui (largura e profundidade) e uma superfície, na dimensão de que carece (a profundidade). Esta concepção é fundamental para se perceber algumas passagens do De continuo. 
Não se pode dizer que Bradwardine foi muito original nos argumentos de ataque ao indivisibilismo que apresenta (ou proposições refutatórias), mas foi-o decididamente nas proposições de carácter "positivo" 46. Num determinado número de proposições do tratado, Bradwardine constrói (a sua concepção do contínuo); noutro, ele destrói (as posições do atomistas). As proposições positivas estão na base da estruturação dedutiva de um corpo de conhecimentos e é por meio destas que a posição doutrinal de Bradwardine é dada a conhecer. No cômputo geral da dimensão do tratado, este núcleo de argumentos não conhece um nível de representatividade tão elevado como o dos dedicados à refutação do atomismo ${ }^{47}$, mas aquela secção de conclusões é de maior relevância.

Aristóteles tem uma presença singular na concepção do contínuo em Bradwardine, embora este a supere ainda. Bradwardine mostra a sua posição relativamente ao problema do contínuo no corolário da Proposição 141, onde se lê: "Todo o contínuo é composto de uma infinidade de contínuos da mesma espécie como aquele" ${ }^{48}$. Assim, se o contínuo em causa é uma linha, por exemplo, ela é composta de uma (potencial) infinidade de linhas. E esta "infinidade de contínuos" componentes da grandeza assumiria então, na linguagem técnica do filósofo, uma relação de "imposição" assegurando a continuidade da quantidade. Podemos apreciar a posição aristotélica assumida por este autor, que corrobora as concepções centrais do Estagirita relativamente à temática do contínuo (a existência dos limites comuns entre as partes componentes do mesmo e a infinita divisibilidade da grandeza) reinterpretando-as à luz da geometria. Por meio da impositio, Bradwardine explica a conexão que se estabelece entre as partes de um contínuo. Quanto à explicação de como é que se pode dar

46 In J. Murdoch, Geometry and the Continuum in the Fourteenth Century: a Philosophical Analysis of Thomas Bradwardine's Tractatus de Continuo (1957), p. 224:

"...his originality and insight were not so outstanding as the profound looking structure of the De continuo might lead one to expect. The kind of sample, successful propositions (...) are to be found in numerous other Scholastic treatises. Bradwardine's originality (...) is to be found, rather, in the clearer, geometrical meaning he gives to the relations between indivisibles, and in the geometrical demonstrations he gives of the positive properties of continua. How indivisibles might be put together to constitute a continuum, how continua may be shown to be infinitely divisible, and how the parts of continua may be said to be connected, all (...) through Bradwardine's ever-present tendency to think in geometrical terms".

47 “....in order to arrive at his 'definitive' refutation of indivisibilism, he has to establish a number of 'positive' propositions from which the invalidation of his opponents' theses may be deduced. These positive propositions constitute but about one-third of the De Continuo", J. Murdoch, Geometry and the Continuum in the Fourteenth Century: a Philosophical Analysis of Thomas Bradwardine's Tractatus de Continuo (1957), p. 51.

48 “Omne continuum ex infinitis continuis similis speciei cum illo componi”. 
conta da demarcação das diferentes partes de um contínuo, se estas são em número infinito, Bradwardine não apresenta uma resposta esclarecedora, pois ele - tal como Aristóteles - refere o modo como se pode operar a distinção de algumas partes do todo unificado mas não como é que cada uma das partes do contínuo se distingue de todas as restantes partes existentes no mesmo ${ }^{49}$.

\section{RESUMO}

Este artigo pretende abordar o problema do continuum e da defesa de um atomismo matemático no contexto de um tratado medieval do século XIV, de Tomás Bradwardine. A distinção entre as noções de "superpositio" e "impositio" serão colocadas em destaque, bem como o argumento aristotélico contra a possibilidade de contacto entre os pontos. Mostrar-se-á como a noção de continuidade sai reinterpretada no Tractatus de Continuo de Bradwardine, à luz da geometria.

\section{ABSTRACT}

This paper is an approach to the continuum's problem and the defence of a mathematical atomism in the context of a medieval treatise of the fourteenth century. We will focus on the Aristotelian argument against the contact between points and the distinction between the notions of "superpositio" and "impositio" will be explained. We will show how the notion of continuity is reinterpreted in Bradwardine's Tractatus de continuo, in the light of geometry.

$49 \mathrm{Um}$ desenvolvimento desta questão pode ler-se em J. Murdoch, Geometry and the Continuum in the Fourteenth Century: a Philosophical Analysis of Thomas Bradwardine's Tractatus de Continuo (1957), pp. 305-316. 